Original Research Paper

\title{
The Impact of Virtual Classes on Students' Performance in Open Learning Environments: The Case of Arab Open University, Saudi Arabia
}

\author{
Khaled Suwais and Ali Alshahrani \\ Faculty of Computer Studies, Arab Open University, Riyadh, Saudi Arabia
}

\author{
Article history \\ Received: 21-11-2017 \\ Revised: 23-12-2017 \\ Accepted: 3-01-2018 \\ Corresponding Author: \\ Khaled Suwais \\ Faculty of Computer Studies, \\ Arab Open University, Riyadh, \\ Saudi Arabia \\ Email: khaled.suwais@arabou.edu.sa
}

\begin{abstract}
Open learning aims to deliver different educational services and activities for learners throughout an organised set of policies and procedures. The ultimate objective of such policies is to minimise the geographical and time limitations that might affect the students' performance during his or her academic life. The Arab Open University in Saudi Arabia is one of the leading universities that deliver open learning education in the Middle East. To achieve its mission, AOU utilises virtual classes' technologies as a teaching mode for its learners. In this study, we study and analyse the students' academic performance in virtual classes against the traditional face-to-face classes. The usefulness of this study arises from its importance in directing the decision makers at AOU of the efficiency of virtual classes as a delivery mode of teaching and a set of recommendation for future enhancement.
\end{abstract}

Keywords: Open Learning, Virtual Classes, Learning Environment, Higher Education

\section{Introduction}

The core of open learning depends on delivering the teaching services for students throughout organised policies and procedures. These policies aim to minimise the geographical and time limitations that might affect students during the academic life.

One of the teaching services that is a point of concern for many learners and academic institutions is the method of delivering the teaching materials for the online-based interaction. Unlike distance learning (online learning) and traditional learning (face-to-face learning), open learning introduces a balanced learning system that combines both face-to-face meetings and online interaction between the learners and tutors to achieve the academic objectives (Larson and Murray, 2017; Asoodar et al., 2014).

Attending online meetings (denoted by Virtual Classes) aims to facilitate a smooth real-time interaction between learners and tutors with the support of new technologies and IT infrastructure (Spoelstra et al., 2015). The virtual classes were affected by many factors, including the speed of the internet connection and the quality of the software used for conducting these virtual classes. As the technology advance, the limitations are minimised or even eliminated to some extent. The robustness of internet connections is found to be more enhanced and the special-purpose software is well-designed to support virtual classes' activities.

The Arab Open University (AOU) is one of the leading universities in the Arab region that offer higher education programs based on an open learning system. The AOU utilises up-to-date technologies to deliver high-quality virtual classes for students located across different cities. Official reports by AOU reveal that students are worried about using virtual classes as a teaching mode as it might affect their academic performance; compared to the face-toface meetings. Accordingly, this paper focuses on studying and analysing the impact of virtual classes on students' academic performance, the AOU in Saudi Arabia as a case study. The ultimate objective of this study is to enhance the educational process by evaluating the teaching services which meet the learners' needs. However, evaluating the virtual classes as a service could be possible by examining the impact of virtual classes on the students' academic performances, identifying the factors which might affect the quality of virtual classes and the relation between the difficulty level of the courses (offered as virtual class) and the students' academic performance. 


\section{Overview of the Open Learning Environment}

Open education integrates resources, tools and practises for sharing information by improving efficient access across the world (Shaw, 2013). Therefore, the philosophy of AOU is formed based on the importance of open learning which emerges from its capability in fulfilling people's desire for education.

As open education depends on online services, different free tools that are used in teaching and learning are available on the internet for anybody at no cost. Such materials are referred to as Open Education Resources (OER). According to (Mosselly, 2013; Santos, 2010), OER may include documents, digital images and videostextbooks among others. These resources can be used and reused since they are published freely on the internet.

Larson and Murray (2017), the authors confirmed that schools have also incorporated open learning as they dictate notes in class and also use visual aids for the same. In open learning, teachers and students can e-conference each other and have a productive lesson and also through the use of emails for questions and feedbacks.

From the other perspective, Beek (2011) expounds the different ways in which technology is being used to make learning better for students and teachers. For instance, teachers can use computer software to pass on instructions to the students, unlike the traditional method where teachers dictated the instructions themselves. The virtual technology of open learning enables both the teacher and student to work in the comfort of their homes with no restriction to a certain routine that they have to follow.

The impact of virtual learning as a method of open learning may vary from one learner to another. Barker and Gossman (2013), the authors state that the virtual learning environment assigns students tasks to carry out at their own pace and time. The positive aspect of such a trend is that students perform better both in open learningschool based. It maximizes a students' critical thinking and creativity skills.

In this context, the Arab Open University uses advanced technologies for supporting virtual learning activities. One of these activities is the virtual classes, which aims at delivering high-quality real-time video streaming for students across the cities of Saudi Arabia. This feature facilitates sharing the knowledge among different learners in different geographical locations. AOU uses the latest e-podium (an equipped smart computing station) technology that can store and broadcast a wide range of video and audio media in a safe and convenient way (PeopleLink e-Podium, 2017). This smart station enables the tutor to deliver a virtual class for the learners using an interactive screen equipped with a complete set of tools. Whatever the tutor writes or draws on the interactive screen, it will directly be replicated on the learners' screen. This technology increases the level of collaboration between the tutor and the learner, on the one hand and on the other hand, widens the range of courses that can be delivered to the learners. This includes Math, Physics, Engineering and many other courses.

The virtual learning environment at $\mathrm{AOU}$ integrates the use of the Virtual Class (VC) with a Learning Management System (LMS) that supports the education process with a set of well-defined academic activities. The LMS is designed to assure proper space of collaboration between the students themselves and the students with their corresponding tutors. This is possible through the online forums which are assigned for every single course offered on LMS. The online forums along with other supporting materials published on LMS represent the backbone of virtual classes in the virtual learning environment of the AOU educational system as in other educational institutions (Zhang et al., 2014).

As mentioned earlier, the impact of virtual learning may differ from one learner to another. From this point, we believe that a comprehensive analysis of the impact of $\mathrm{VC}$ on the students' academic performance is worth studying. We aim to critically analyse the students' academic performance in different courses offered in different academic years. This study helps the decision makers at AOU to evaluate their academic plans and strategies concerning the use of $\mathrm{VC}$ as a means for delivering classes.

\section{Methodology}

The research method used in this study is based on analysing the academic performance of AOU students statistically. An intensive analysis was made to identify the list of courses that can be included in this study. Identifying the candidate courses was made by tracking the set of courses offered as virtual classes in some semesters and as face-to-face classes in other semesters. We focused on the courses offered in the last two academic years (2015/2016 and 2016/2017) as the IT infrastructure at AOU became perfectly stable and reliable. The identified courses are also selected such that they vary in the level of difficulty as shown in Table 1 . The reason behind selecting these particular courses is due to the nature of these courses. They vary between practical courses (e.g., programming and mathematics) and theoretical courses (e.g., concepts and discussions).

Three primary factors are considered to assist in judging the efficiency of virtual classes on the students' academic performance. The first factor is the pass rate of the students in $\mathrm{VC}$ classes compared to Face-to-Face (F2F) classes. This factor measures the students' academic performance, such that the higher the pass rate, the better is that teaching method compared to the other one. The pass rates are 
compared between students attending the $\mathrm{VC}$ classes against students attending F2F classes of the same courses throughout the two academic years.

The second factor is the courses' drop rates. This factor measures the level of satisfaction from the students' perspective. Students will generally drop courses when they do not feel satisfied with the teaching services being provided or they think they won't achieve their academic targets in that particular course. Accordingly, a lower drop rate indicates a higher efficiency of that particular teaching method.

The third factor is the average grade of students in each course. This factor is chosen to give us a general overview of the students' academic performance as groups. This factor is essential to measure the level of collaboration among students in the same class. Achieving higher average grades in the VC mode indicate that the collaboration level is not affected by the teaching method of delivery. However, Fig. 1 illustrates the relationship between the three factors and the level of difficulties of the selected courses in this study.

\section{Statistical Experiments}

In this study, three statistical methods are used to examine the three test factors against the students' results obtained in the courses offered as $\mathrm{VC}$ and $\mathrm{F} 2 \mathrm{~F}$ classes. The statistical methods are the mean, standard deviation and independent sample T-Test. The sample size is 200 students selected from 1,000 students that studied in the two academic years 2015/2016 and $2016 / 2017$. The gender of the selected students is found to be $58 \%$ male students and $42 \%$ female students. In this section, we present our statistical results with comprehensive discussions on our findings. With reference to the list of courses in Table 1 and the testing model illustrated in Fig. 1, we statistically analyse each course, according to the testing three factors considered in this study.

\section{The Performance of Students in Course M180}

Starting with the course M180, Table 2 shows that the students' pass rate of M180-F2F is a bit higher than the pass rate of M180-VC. At the same time, the drop rate of students in M180-F2F is found a bit higher than the drop rate of M180-VC. However, the T-Test results presented in Table 3 shows that the differences between the two samples are not statistically significant.

The average grade of the students in M180 is also tested. The results in Table 4 show that the mean grade of M180-F2F is 68.00 , while in M180-VC it is found to be 64.50. The T-Test results presented in Table 4 shows that the difference is statistically significant for a $p$ value of 0.01 . This means the students in M180-F2F could achieve a higher average grade compared to the students in M180-VC.

\section{The Performance of Students in Course M150A}

For the other level 1 course M150A, Table 5 shows that the students' pass rate of M150A-VC is higher than the pass rate of M150A-F2F. On the other hand, the drop rate of students in M150A-F2F is found also higher than the drop rate of $\mathrm{M} 150 \mathrm{~A}-\mathrm{VC}$. The T-Test results presented in Table 6 shows that the difference between the two samples is statistically significant.

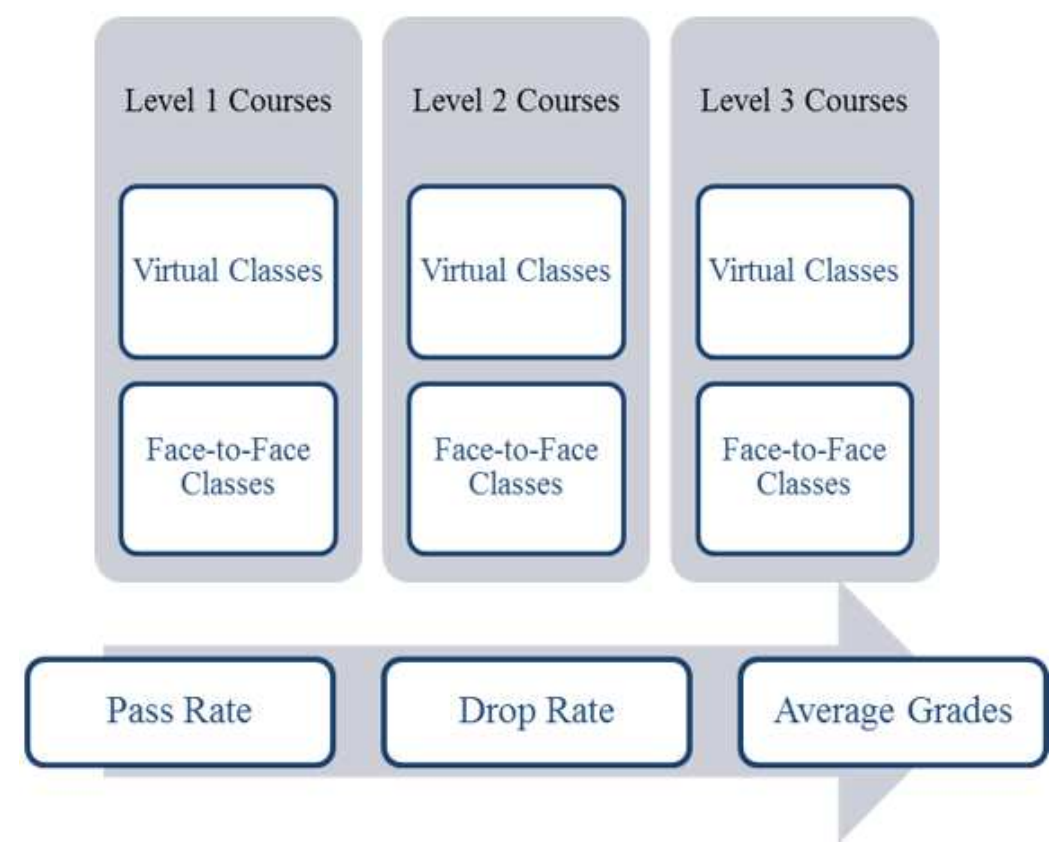

Fig. 1: The overall testing model of our method 


\begin{tabular}{|c|c|c|}
\hline $\begin{array}{l}\text { Course } \\
\text { code }\end{array}$ & Course title & $\begin{array}{l}\text { Course level } \\
\text { (out of } 3 \text { levels }\end{array}$ \\
\hline M180 & Data structure and algorithms & 1 \\
\hline M150A & $\begin{array}{l}\text { Data, computing } \\
\text { and information (I) }\end{array}$ & 1 \\
\hline M150B & $\begin{array}{l}\text { Data, computing } \\
\text { and information (II) }\end{array}$ & 1 \\
\hline $\mathrm{T} 175 \mathrm{~A}$ & Networked living (I) & 1 \\
\hline T175B & Networked living (II) & 1 \\
\hline T103 & $\begin{array}{l}\text { Computer architecture } \\
\text { and logic design }\end{array}$ & 1 \\
\hline M253 & $\begin{array}{l}\text { Teamwork in } \\
\text { distributed environment }\end{array}$ & 2 \\
\hline $\mathrm{T} 215 \mathrm{~A}$ & $\begin{array}{l}\text { Communications and } \\
\text { information } \\
\text { technologies (I) }\end{array}$ & 2 \\
\hline TT284 & Web technologies & 2 \\
\hline T324 & Keeping ahead in ITC & 3 \\
\hline
\end{tabular}

Table 2: Pass rates and drop rates of M180 using VC and F2F study modes

\begin{tabular}{|c|c|c|c|c|c|}
\hline \multirow[b]{2}{*}{ Course } & \multirow[b]{2}{*}{ Mode } & \multicolumn{2}{|c|}{ Pass rate } & \multicolumn{2}{|c|}{ Drop rate } \\
\hline & & No. & $\%$ & No. & $\%$ \\
\hline \multirow[t]{2}{*}{ M180 } & $\mathrm{VC}$ & 162 & 81.00 & 19 & 9.50 \\
\hline & $\mathrm{F} 2 \mathrm{~F}$ & 179 & 89.50 & 6 & 3.00 \\
\hline
\end{tabular}

Table 3: T-Test results on pass rates and drop rates of M180

\begin{tabular}{lllllll}
\hline Course & Mode & Mean & $\begin{array}{l}\text { Std. } \\
\text { Dev. }\end{array}$ & df & T value & $\begin{array}{c}\text { Sig. 2- } \\
\text { tailed }\end{array}$ \\
\hline M180 & VC & 2.72 & 0.63 & 398 & 1.78 & 0.076 \\
& F2F & 2.82 & 0.55 & & & \\
\hline
\end{tabular}

Table 4: T-Test results on the average grades of M180

\begin{tabular}{lllllll}
\hline Course & Mode & Mean & $\begin{array}{l}\text { Std. } \\
\text { Dev. }\end{array}$ & df & T value & $\begin{array}{l}\text { Sig. 2- } \\
\text { tailed }\end{array}$ \\
\hline M180 & VC & 64.5 & 7.52 & 398 & 6.53 & 0 \\
& F2F & 68 & 1 & & & \\
\hline
\end{tabular}

Table 5: Pass rates and drop rates of M150A using VC and F2F study modes

\begin{tabular}{llllcr}
\hline & & Pass rate & \multicolumn{2}{c}{ Drop rate } \\
\cline { 3 - 5 } Course & Mode & No. & \% & No. & \multicolumn{1}{c}{$\%$} \\
\hline M150A & VC & 68 & 68.00 & 6 & 6.00 \\
& F2F & 113 & 37.70 & 49 & 16.30 \\
\hline
\end{tabular}

Table 6: T-Test results on pass rates and drop rates of M150A

\begin{tabular}{lllllll}
\hline Course & Mode & Mean & $\begin{array}{l}\text { Std. } \\
\text { Dev. }\end{array}$ & df & T value & $\begin{array}{l}\text { Sig. 2- } \\
\text { tailed }\end{array}$ \\
\hline M150A & VC & 2.42 & 0.88 & 498 & 4.82 & 0 \\
& F2F & 1.92 & 0.91 & & & \\
\hline
\end{tabular}

Table 7: T-Test results on the average grades of M150A

\begin{tabular}{ccccccl}
\hline Course & Mode & Mean & $\begin{array}{l}\text { Std. } \\
\text { Dev. }\end{array}$ & df & T value & $\begin{array}{l}\text { Sig. 2- } \\
\text { tailed }\end{array}$ \\
\hline M150A VC & 56.00 & 0.00 & 398 & 33.63 & 0 \\
& F2F & 45.67 & 5.32 & & & \\
\hline
\end{tabular}

The average grade of the students in M150A is also tested. The results in Table 7 show that the mean grade of M150A-F2F is 45.67, while in M150A-VC it is found to be 56.00. The T-Test results presented in Table 7 shows that the difference is statistically significant for a $p$-value of 0.01 . This means the students in M150A-VC could achieve a higher average grade compared to the students in M150A-F2F.

\section{The Performance of Students in Course M150B}

For the second part of the course M150, the students' performance in M150B is tested. Table 8 shows that the students' pass rate of $\mathrm{M} 150 \mathrm{~B}-\mathrm{VC}$ is similar to the pass rate of M150B-F2F. On the other hand, the drop rate of students in M150B-F2F is found a bit higher than the drop rate of M150B-VC. The T-Test results presented in Table 9 show that the difference between the two samples is not statistically significant.

The average grade factor of all students in M150B is also tested. The results in Table 10 show that the mean grade of M150B-F2F is 64.00 , while in M150B-VC it is found to be 59.5. The T-Test results presented in Table 10 show that the difference is statistically significant for a $p$-value of 0.01 . This means the students in M150B$\mathrm{F} 2 \mathrm{~F}$ could achieve a higher average grade compared to the students in M150B-VC.

\section{The Performance of Students in Course T175A}

For next course in this analysis is $\mathrm{T} 175 \mathrm{~A}$, the students' performance in T175A is statistically tested. Table 11 shows that the students' pass rate of T175AF2F is a bit higher than the pass rate of T175A-VC. At the same time, the drop rate of students in T175A-VC is found also a bit higher than the drop rate of T175A-F2F. However, the T-Test results presented in Table 12 show that the difference between the two samples is not statistically significant.

The average grade factor of all students in T175A is tested. The results in Table 13 show that the mean grade of T175A-F2F is 58.5, while in T175A-VC it is found to be 59.0. The T-Test results presented in Table 13 show that the difference is not statistically significant for a $p$ value of 0.01 . This means the students in T175A-F2F could achieve a similar average grade as the students in T175A-VC.

\section{The Performance of Students in Course T175B}

The second part of the course T175 is T175B. The students' performance in T175B is statistically tested. Table 14 shows that the students' pass rate of T175B-VC is a bit higher than the pass rate of T175B-F2F. At the same time, the drop rate of students in T175B-VC is found also a bit higher than the drop rate of T175B-F2F. However, the T-Test results presented in Table 15 show that the difference between the two samples is not statistically significant for a $p$-value of 0.01 . 
Table 8: Pass rates and drop rates of $\mathrm{M} 150 \mathrm{~B}$ using $\mathrm{VC}$ and F2F study modes

\begin{tabular}{|c|c|c|c|c|c|}
\hline \multirow[b]{2}{*}{ Course } & \multirow[b]{2}{*}{ Mode } & \multicolumn{2}{|c|}{ Pass rate } & \multicolumn{2}{|c|}{ Drop rate } \\
\hline & & No. & $\%$ & No. & $\%$ \\
\hline \multirow[t]{2}{*}{ M150B } & $\mathrm{VC}$ & 146 & 73.00 & 4 & 2.00 \\
\hline & F2F & 146 & 73.00 & 15 & 7.50 \\
\hline
\end{tabular}

Table 9: T-Test results on pass rates and drop rates of M150B

\begin{tabular}{|c|c|c|c|c|c|c|}
\hline Course & Mode & Mean & $\begin{array}{l}\text { Std. } \\
\text { Dev. }\end{array}$ & df & $\mathrm{T}$ value & $\begin{array}{l}\text { Sig. 2- } \\
\text { tailed }\end{array}$ \\
\hline \multirow[t]{2}{*}{ M150B } & $\mathrm{VC}$ & 2.48 & 0.87 & 398 & 0.66 & 0.511 \\
\hline & $\mathrm{F} 2 \mathrm{~F}$ & 2.54 & 0.80 & & & \\
\hline
\end{tabular}

Table 10: T-Test results on the average grades of M150B

\begin{tabular}{lllllll}
\hline Course & Mode & Mean & $\begin{array}{l}\text { Std. } \\
\text { Dev. }\end{array}$ & df & T value & $\begin{array}{l}\text { Sig. 2- } \\
\text { tailed }\end{array}$ \\
\hline M150B & VC & 59.5 & 3.51 & 398 & 15.75 & 0 \\
& F2F & 64 & 2.01 & & & \\
\hline
\end{tabular}

Table 11: Pass rates and drop rates of $\mathrm{T} 175 \mathrm{~A}$ using $\mathrm{VC}$ and F2F study modes

\begin{tabular}{|c|c|c|c|c|c|}
\hline \multirow[b]{2}{*}{ Course } & \multirow[b]{2}{*}{ Mode } & \multicolumn{2}{|c|}{ Pass rate } & \multicolumn{2}{|c|}{ Drop rate } \\
\hline & & No. & $\%$ & No. & $\%$ \\
\hline \multirow[t]{2}{*}{$\mathrm{T} 175 \mathrm{~A}$} & $\mathrm{VC}$ & 131 & 65.50 & 24 & 12.00 \\
\hline & $\mathrm{F} 2 \mathrm{~F}$ & 414 & 69.00 & 47 & 7.80 \\
\hline
\end{tabular}

Table 12: T-Test results on pass rates and drop rates of T175A

\begin{tabular}{lllllll}
\hline Course & Mode & Mean & $\begin{array}{l}\text { Std. } \\
\text { Dev. }\end{array}$ & df & T value & $\begin{array}{l}\text { Sig. 2- } \\
\text { tailed }\end{array}$ \\
\hline T175A & VC & 2.43 & 0.84 & 798 & 0.41 & 0.68 \\
& F2F & 2.46 & 0.84 & & & \\
\hline
\end{tabular}

Table 13: T-Test results on the average grades of T175A

\begin{tabular}{|c|c|c|c|c|c|c|}
\hline Course & Mode & Mean & $\begin{array}{l}\text { Std. } \\
\text { Dev. }\end{array}$ & $\mathrm{df}$ & $\mathrm{T}$ value & $\begin{array}{l}\text { Sig. 2- } \\
\text { tailed }\end{array}$ \\
\hline \multirow[t]{2}{*}{$\mathrm{T} 175 \mathrm{~A}$} & $\mathrm{VC}$ & 59.0 & 7.02 & 798 & 0.86 & 0.389 \\
\hline & F2F & 58.5 & 7.33 & & & \\
\hline
\end{tabular}

Table 14: Pass rates and drop rates of T175B using VC and F2F study modes

\begin{tabular}{|c|c|c|c|c|c|}
\hline \multirow[b]{2}{*}{ Course } & \multirow[b]{2}{*}{ Mode } & \multicolumn{2}{|c|}{ Pass Rate } & \multicolumn{2}{|c|}{ Drop Rate } \\
\hline & & No. & $\%$ & No. & $\%$ \\
\hline \multirow[t]{2}{*}{ T175B } & $\mathrm{VC}$ & 148 & 74.00 & 17 & 8.50 \\
\hline & F2F & 141 & 70.50 & 10 & 5.00 \\
\hline
\end{tabular}

Table 15: T-Test results on pass rates and drop rates of T175B

\begin{tabular}{|c|c|c|c|c|c|c|}
\hline Course & Mode & Mean & $\begin{array}{l}\text { Std. } \\
\text { Dev. }\end{array}$ & $\mathrm{df}$ & $\mathrm{T}$ value & $\begin{array}{l}\text { Sig. 2- } \\
\text { tailed }\end{array}$ \\
\hline \multirow[t]{2}{*}{ T175B } & $\mathrm{VC}$ & 2.57 & 0.77 & 398 & 1.28 & 0.2 \\
\hline & $\mathrm{F} 2 \mathrm{~F}$ & 2.46 & 0.86 & & & \\
\hline
\end{tabular}

Table 16: T-Test results on the average grades of T175B

\begin{tabular}{|c|c|c|c|c|c|c|}
\hline Course & Mode & Mean & $\begin{array}{l}\text { Std. } \\
\text { Dev. }\end{array}$ & $\mathrm{df}$ & $\mathrm{T}$ value & $\begin{array}{l}\text { Sig. 2- } \\
\text { tailed }\end{array}$ \\
\hline \multirow[t]{2}{*}{ T175B } & $\mathrm{VC}$ & 61.5 & 1.50 & 398 & 18.52 & 0 \\
\hline & $\mathrm{F} 2 \mathrm{~F}$ & 56.5 & 3.51 & & & \\
\hline
\end{tabular}

The average grade factor of all students in T175B is tested. The results in Table 16 show that the mean grade of T175B-F2F is 56.5 , while in T175B-VC it is found to be 61.5. The T-Test results presented in Table 16 show that the difference is statistically significant for a $p$-value of 0.01 . This means the students in T175B-VC could achieve a higher average grade compared to the students in T175B-F2F.

\section{The Performance of Students in Course T103}

In this section, the students' performance in T103 is statistically tested. Table 17 shows that the students' pass rate of T103-F2F is higher than the pass rate of T103-VC. On the other hand, the drop rate of students in T103-VC is found also higher than the drop rate of T103-F2F. However, the T-Test results presented in Table 18 show that the difference between the two samples is statistically significant for a $p$-value of 0.01 .

The average grade factor of all students in T103 is also tested. The results in Table 19 show that the mean grade of T103-F2F is 79.0, while in T103-VC it is found to be 61.67. The T-Test results show that the difference is statistically significant for a $p$-value of 0.01 . This means the students in T103-F2F could achieve higher average grade compared to the students in T103-VC.

\section{The Performance of Students in Course M253}

In this section, the students' performance in M253 (level 2 course) is statistically tested. Table 20 shows that the students' pass rate of M253-VC is higher than the pass rate of M253-F2F. On the other hand, the drop rate of students in M253-F2F is found higher than the drop rate of $\mathrm{M} 253-\mathrm{VC}$. The T-Test results presented in Table 21 show that the difference between the two samples is statistically significant for a $p$-value of 0.01 .

The average grade factor of all students in M253 is also tested. The results in Table 22 show that the mean grade of M253-F2F is 64.0, while in M253-VC it is found to be 74.00. The T-Test results show that the difference is statistically significant for a p-value of 0.01 . This means the students in M253-VC could achieve a higher average grade compared to the students in M253-F2F.

\section{The Performance of Students in Course T215A}

Another level 2 course is tested in this section. The students' performance in T215A is statistically tested. Table 23 shows that the students' pass rate of T215A$\mathrm{F} 2 \mathrm{~F}$ is higher than the pass rate of T215A-VC. On the other hand, the drop rate of students in T215A-F2F is found similar to the drop rate of T215A-VC. The T-Test results presented in Table 24 show that the difference between the two samples is statistically significant for a $p$-value of 0.01 . 
Table 17: Pass rates and drop rates of $\mathrm{T} 03$ using $\mathrm{VC}$ and $\mathrm{F} 2 \mathrm{~F}$ study modes

\begin{tabular}{|c|c|c|c|c|c|}
\hline \multirow[b]{2}{*}{ Course } & \multirow[b]{2}{*}{ Mode } & \multicolumn{2}{|c|}{ Pass rate } & \multicolumn{2}{|c|}{ Drop rate } \\
\hline & & No. & $\%$ & No. & $\%$ \\
\hline \multirow[t]{2}{*}{ T103 } & VC & 210 & 70.00 & 29 & 9.70 \\
\hline & $\mathrm{F} 2 \mathrm{~F}$ & 95 & 95.00 & 0 & 0.00 \\
\hline
\end{tabular}

Table 18: T-Test results on pass rates and drop rates of T103

\begin{tabular}{lllllll}
\hline Course & Mode & Mean & $\begin{array}{l}\text { Std. } \\
\text { Dev. }\end{array}$ & df & T value & $\begin{array}{l}\text { Sig. 2- } \\
\text { tailed }\end{array}$ \\
\hline T103 & VC & 2.5 & 0.81 & 398 & 6.29 & 0 \\
& F2F & 2.9 & 0.44 & & & \\
\hline
\end{tabular}

Table 19: T-Test results on the average grades of T103

\begin{tabular}{lllllll}
\hline Course & Mode & Mean & $\begin{array}{l}\text { Std. } \\
\text { Dev. }\end{array}$ & df & T value & $\begin{array}{l}\text { Sig. 2- } \\
\text { tailed }\end{array}$ \\
\hline T103 & VC & 61.67 & 7.15 & 398 & 42.02 & 0 \\
& F2F & 79 & 0 & & &
\end{tabular}

Table 20: Pass rates and drop rates of $\mathrm{M} 253$ using $\mathrm{VC}$ and F2F study modes

\begin{tabular}{llllll}
\hline & & Pass rate & \multicolumn{2}{l}{ Drop rate } \\
& & - & - & \\
Course & Mode & No. & \% & No. & \% \\
\hline M253 & VC & 180 & 90.00 & 4 & 2.00 \\
& F2F & 157 & 78.50 & 10 & 5.00 \\
\hline
\end{tabular}

Table 21: T-Test results on pass rates and drop rates of M253

\begin{tabular}{lllllll}
\hline Course & Mode & Mean & Dev. & Df & T value & $\begin{array}{c}\text { Sig. 2- } \\
\text { tailed }\end{array}$ \\
\hline M253 & VC & 2.82 & 0.56 & 398 & 3.02 & 0.003 \\
& F2F & 2.62 & 0.75 & & & \\
\hline
\end{tabular}

Table 22: T-Test results on the average grades of M253

\begin{tabular}{lllllll}
\hline Course & Mode & Mean & $\begin{array}{l}\text { Std. } \\
\text { Dev. }\end{array}$ & Df & T value & $\begin{array}{l}\text { Sig. 2- } \\
\text { tailed }\end{array}$ \\
\hline M253 & VC & 74 & 13.03 & 398 & 8.6 & 0 \\
& F2F & 64 & 10.03 & & & \\
\hline
\end{tabular}

Table 23: Pass rates and drop rates of T215A using VC and F2F study modes

\begin{tabular}{llllll}
\multicolumn{3}{c}{ F2F study modes } \\
& & Pass rate & \multicolumn{2}{l}{ Drop rate } \\
Course & Mode & No. & $\%$ & No. & \% \\
\hline T215A & VC & 143 & 71.50 & 15 & 7.50 \\
& F2F & 170 & 85.00 & 15 & 7.50 \\
\hline
\end{tabular}

Table 24: T-Test results on pass rates and drop rates of T215A

\begin{tabular}{lllllll}
\hline Course & Mode & Mean & $\begin{array}{l}\text { Std. } \\
\text { Dev. }\end{array}$ & Df & T value & $\begin{array}{l}\text { Sig. 2- } \\
\text { tailed }\end{array}$ \\
\hline T215A & VC & 2.51 & 0.82 & 398 & 3.82 & 0 \\
& F2F & 2.78 & 0.57 & & & \\
\hline
\end{tabular}

Table 25: T-Test results on the average grades of T215A

\begin{tabular}{lllllll}
\hline Course & Mode & Mean & $\begin{array}{l}\text { Std. } \\
\text { Dev. }\end{array}$ & df & T value & $\begin{array}{c}\text { Sig. 2- } \\
\text { tailed }\end{array}$ \\
\hline T215A & VC & 62 & 1 & 398 & 12.62 & 0 \\
& F2F & 64 & 2.01 & & & \\
\hline
\end{tabular}

Table 26: Pass rates and drop rates of TT284 using VC and F2F study modes

\begin{tabular}{|c|c|c|c|c|c|}
\hline \multirow[b]{2}{*}{ Course } & \multirow[b]{2}{*}{ Mode } & \multicolumn{2}{|c|}{ Pass rate } & \multicolumn{2}{|c|}{ Drop rate } \\
\hline & & No. & $\%$ & No. & $\%$ \\
\hline \multirow[t]{2}{*}{ TT284 } & $\mathrm{VC}$ & 64 & 64.00 & 4 & 4.00 \\
\hline & $\mathrm{F} 2 \mathrm{~F}$ & 189 & 94.50 & 4 & 2.00 \\
\hline
\end{tabular}

Table 27: T-Test results on pass rates and drop rates of TT284

\begin{tabular}{lllllll}
\hline \multirow{2}{*}{ Course } & Mode & Mean & Dev. & df & T value & $\begin{array}{l}\text { Sig. 2- } \\
\text { tailed }\end{array}$ \\
\hline TT284 & VC & 2.32 & 0.93 & 298 & 6.08 & 0 \\
& F2F & 2.91 & 0.39 & & & \\
\hline
\end{tabular}

Table 28: T-Test results on the average grades of TT284

\begin{tabular}{lllllll}
\hline \multirow{2}{*}{ Course } & Mode & Mean & Dev. & df & T value & $\begin{array}{l}\text { Sig. 2- } \\
\text { tailed }\end{array}$ \\
\hline TT284 & VC & 51 & 0 & - & - & - \\
& F2F & 66 & 0 & & & \\
\hline
\end{tabular}

Table 29: Pass rates and drop rates of $\mathrm{T} 324$ using $\mathrm{VC}$ and F2F study modes

\begin{tabular}{llllll}
\hline & & Pass rate & & \multicolumn{2}{l}{ Drop rate } \\
& & - & & \\
Course & Mode & No. & \% & No. & \% \\
\hline T324 & VC & 197 & 65.70 & 11 & 3.70 \\
& F2F & 87 & 87.00 & 9 & 9.00 \\
\hline
\end{tabular}

Table 30: T-Test results on pass rates and drop rates of T324

\begin{tabular}{lllllll}
\hline & & \multicolumn{3}{c}{ Std. } & \multicolumn{3}{c}{$\begin{array}{c}\text { Sig. 2- } \\
\text { Course }\end{array}$} & Mode & Mean & Dev. & df & T value & tailed \\
\hline T324 & VC & 2.35 & 0.92 & 398 & 6.76 & 0 \\
& F2F & 2.83 & 0.47 & & & \\
\hline
\end{tabular}

Table 31: T-Test results on the average grades of T324

\begin{tabular}{lllllll}
\hline & & \multicolumn{3}{c}{ Std. } & \multicolumn{3}{c}{ Sig. 2- } \\
Course & Mode & Mean & Dev. & df & T value & tailed \\
\hline T324 & VC & 53 & 5.9 & 398 & 38.18 & 0 \\
& F2F & 66 & 0 & & & \\
\hline
\end{tabular}

The average grade factor of all students in T215A is also tested. The results in Table 25 show that the mean grade of T215A-F2F is 64.0 , while in T215A-VC it is found to be 62.00. The T-Test results show that the difference is statistically significant for a $p$-value of 0.01 . This means the students in T215A-F2F could achieve a higher average grade compared to the students in T215A-VC.

\section{The Performance of Students in Course TT284}

The last level 2 course TT284 is tested in this section. Table 26 shows that the students' pass rate of TT284F2F is higher than the pass rate of TT284-VC. On the other hand, the drop rate of students in TT284-VC is found a bit higher than the drop rate of TT284-F2F. The T-Test results presented in Table 27 show that the difference between the two samples is statistically significant for a $p$-value of 0.01 .

The average grade factor of all students in TT284 is also tested. The results in Table 28 show that the mean grade of 
TT284-F2F is 66.0 , while in TT284-VC it is found to be 51.00. However, the T-Test on this factor is failed since the standard deviation of the two samples is the same.

\section{The Performance of Students in Course T324}

The last course in this test is the third level course T324. Table 29 shows that the students' pass rate of T324-F2F is higher than the pass rate of T324-VC. On the other hand, the drop rate of students in T324-F2F is also found higher than the drop rate of T324-VC. The TTest results presented in Table 30 show that the difference between the two samples is statistically significant for a $p$-value of 0.01 .

The average grade factor of all students in T324 is also tested. The results in Table 31 show that the mean grade of T324-F2F is 66.0 , while in T324-VC it is found to be 53.00. However, the T-Test results show that the difference is statistically significant. The students of T324-F2F could achieve higher average grades compared to the other group of students.

\section{Results and Discussion}

The statistical analysis shows that most of the differences between the VC and F2F teaching modes are not statistically significant. One can notice that the same course might have high pass rates and average grades while having high drop rates as in T324. The overall results show that there is no clear advantage of one teaching mode to the other mode. In this regard, the statistical results of each factor of the three study's factors are analysed in a general context. Figure 2 visualizes the pass rates achieved by students in both VC and F2F teaching modes.

The figure above shows that the pass rates on most of the courses are similar in the two teaching modes, except for the course M150A which shows much difference for the F2F mode against the VC mode. The reason behind such a gap was investigated and the results show that the faculty had released one of the prerequisites of the course, which allowed unprepared students to register for this course starting from the academic year 2016/2017. Therefore, the teaching mode of this particular course was not the reason behind such differences in the pass rates.

The drop rates of students of VC and F2F teaching modes are also investigated. Figure 3 shows that the drop rates of students in M150A-F2F were much higher due to the reason mentioned earlier (releasing one of the prerequisites). However, one can note that while students progressing from one level to another, the drop rates were significantly decreased. This is a clear indication of the ability of the students to adapt themselves to the VC-based courses.

Concerning the third factor, we found that the average grades of the students in VC classes are almost similar to the students in F2F classes. Figure 4 shows that the students' average grade in VC-based courses is more stable compared to F2F-based courses most of the time, especially for level 1 and 2 courses.

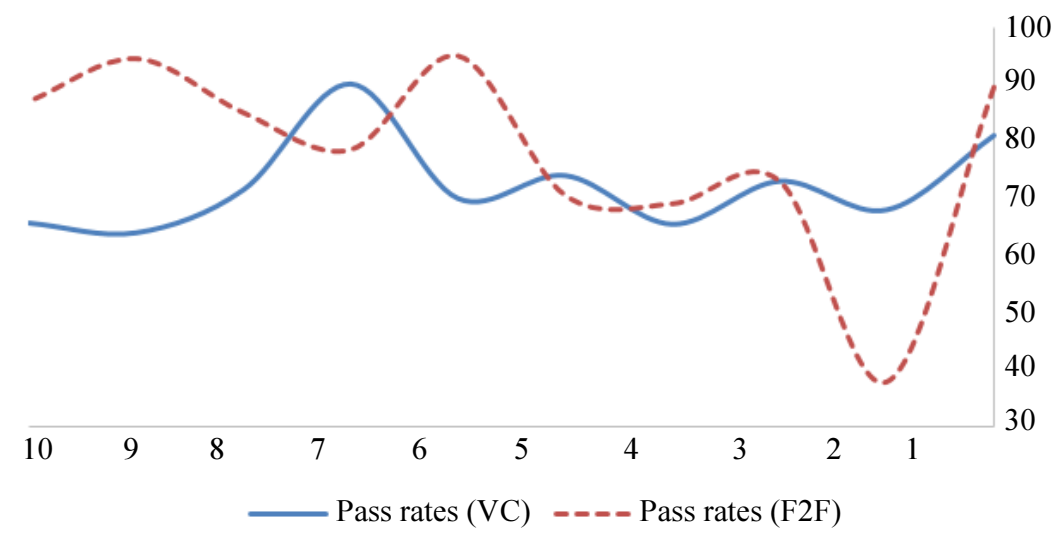

Fig. 2: Pass rates of students in VC versus F2F teaching mode

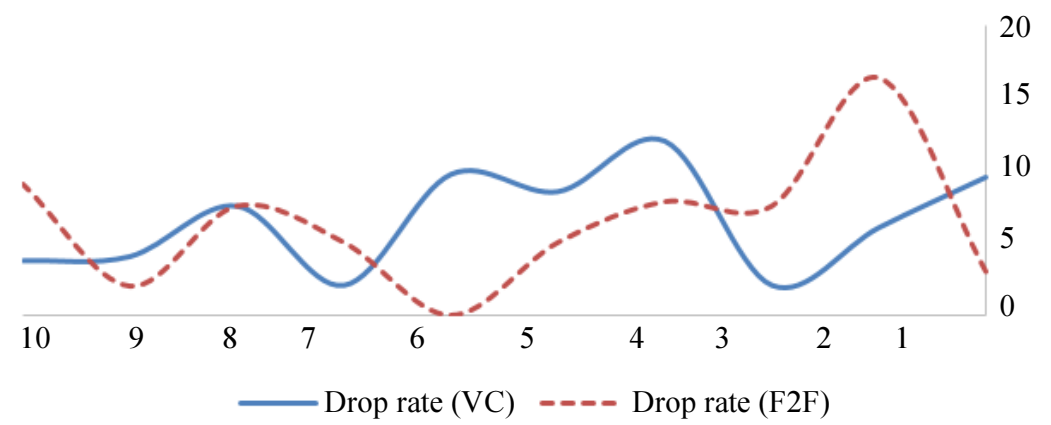

Fig. 3: Drop rates of students in VC versus F2F teaching mode 


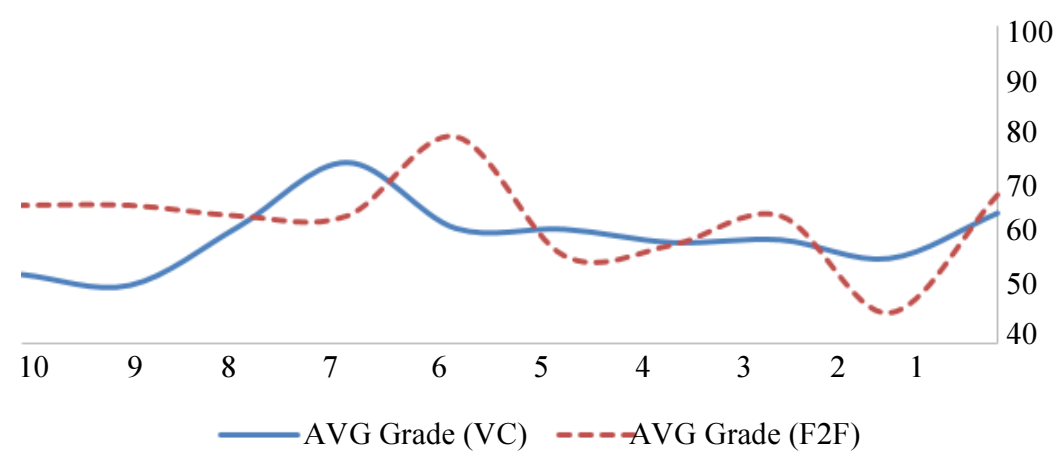

Fig. 4: Average grades of students in VC versus F2F teaching mode

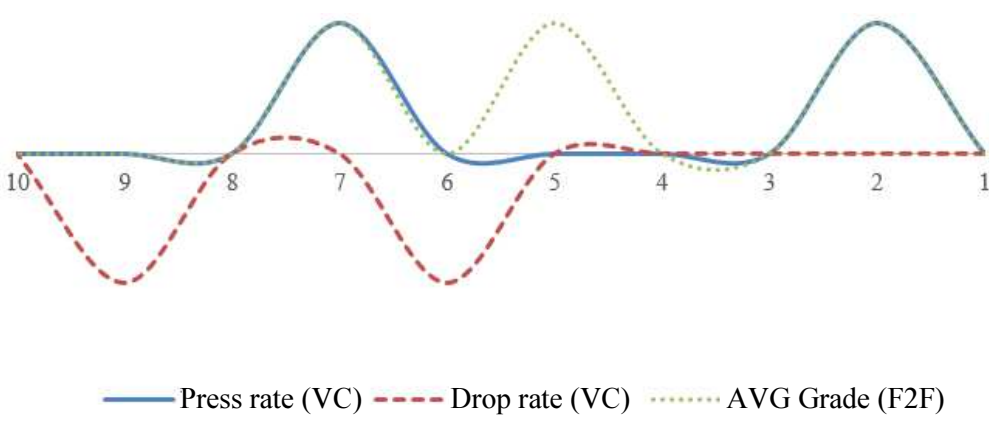

Fig. 5: Overall performance of students in VC-based courses

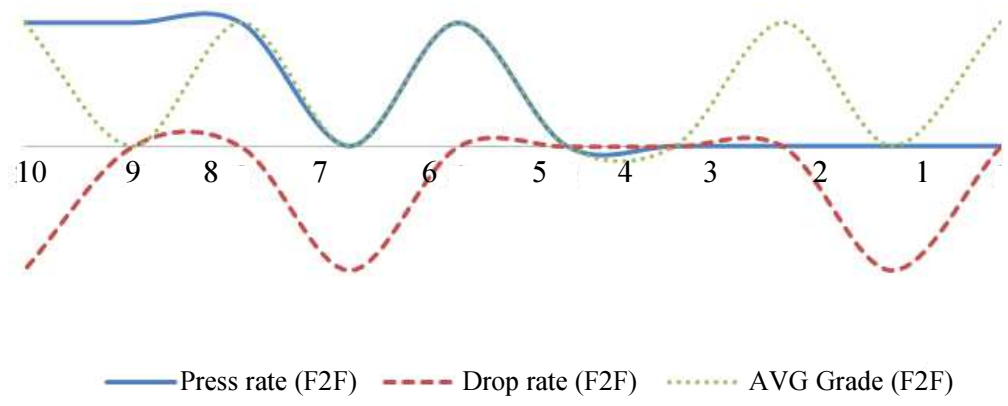

Fig. 6: Overall performance of students in F2F-based courses

In general, we can conclude that the performance of the students in both teaching modes is similar. There is no clear evidence on the preference of one teaching mode to the other mode. One factor might be advantageous for one course in a given teaching mode, while the same factor might be negative in other courses in the same teaching mode. This means that the VC teaching mode has no negative impact on the academic performance of AOU students. Figures 5 and 6 show the overall performance of the students in the three factors using the VC mode and the F2F mode respectively.

\section{Conclusion}

As AOU adopts the open learning philosophy in its educational system, different open learning technologies are used for delivering teaching services and activities. This study focuses on one of these activities, which is the virtual classes. An intensive statistical analysis was carried out to examine the impact of using VC classes on the performance of AOU students from the academic point of view. The results show there is no clear evidence of a negative impact of the VC teaching mode on the students' academic performance. In this regard, the author would recommend that the AOU administration continues using $\mathrm{VC}$ as a teaching mode, which allows the students to acquire knowledge with no geographical or time restrictions.

\section{Acknowledgement}

This study was supported and funded by the Arab 
Open University (AOU), Saudi Arabia.

\section{Author's Contributions}

Khaled Suwais: Writing the manuscript and analyzing relative data. Organizing the research plan is done by this author as well.

Ali Alshahrani: Collecting data and editing the manuscript. States of arts have been conducted by this author as well.

\section{Ethics}

The authors confirm that they abide to all ethical protocols and procedures while preparing this manuscript.

\section{References}

Asoodar, M., S. Marandi, M.R. Atai and S. Vaezi, 2014. Learner reflections in virtual Vs. blended EAP classes. Comput. Human Behav., 41: 533-543. DOI: $10.1016 /$ j.chb.2014.09.050

Barker, J. and P. Gossman, 2013. The learning impact of a virtual learning environment: students' views. Tean J., 5: 19-38.

Beek, M., 2011. What is Virtual Learning. 1st Edn., Mackinac Center For Public Policy.
Larson, R. and E. Murray, 2017. Open educational resources for blended learning in high schools: Overcoming impediments in developing countries. J. Asynchronous Learn. Netw., 12: 85-103.

Mosselly, D., 2013. Open educational resources and open education. The Higher Education Academy. adings/Mossely2013-OERandOpenEducation.pdf

PeopleLink e-Podium, 2017.

Santos, A., 2010. Open educational resources for virtual learning: What works and what doesn't. Open Learning Network Olnet, The Open University UK.

Shaw, M., 2013. Open Education in Practice. In: Openness and Education, Meiszner, A. and L. Squires (Eds.), Emerald Group Publishing Limited, ISBN-10: 978-1-78190-684-2, pp: 25-45.

Spoelstra, H., P. Rosmalen, T. Houtmans and P. Sloep, 2015. Team formation instruments to enhance learner interactions in open learning environments. Comput. Human Behav., 45: 11-20. DOI: $10.1016 /$ j.chb.2014.11.038

Zhang, X., P. de Pablos and Q. Xu, 2014. Culture effects on the knowledge sharing in multi-national virtual classes: A mixed method. Comput. Human Behav., 31: 491-498. DOI: 10.1016/j.chb.2013.04.021 